\title{
BMI open Hospital episode statistics: improving the quality and value of hospital data: a national internet e-survey of hospital consultants
}

\author{
Stephen Andrew Spencer, ${ }^{1}$ Mark Price Davies ${ }^{2}$
}

To cite: Spencer SA, Davies MP. Hospital episode statistics: improving the quality and value of hospital data: a national internet esurvey of hospital consultants. BMJ Open 2012;2:e01651. doi:10.1136/bmjopen-2012001651

- Prepublication history for this paper are available online. To view these files please visit the journal online (http://dx.doi.org/10.1136/ bmjopen-2012-001651)

Received 5 July 2012 Accepted 11 October 2012

This final article is available for use under the terms of the Creative Commons Attribution Non-Commercial 2.0 Licence; see http://bmjopen.bmj.com

\footnotetext{
${ }^{1}$ National Clinical Lead for Hospital Specialties, The Information Centre for Health and Social Care,

NHS Information Centre, Q5 Leeds, UK

${ }^{2}$ Medical Director, The Information Centre for Health and Social Care, NHS Information Centre, Leeds, UK
}

Correspondence to Dr Stephen Andrew Spencer; andy.spencer@doctors.net.uk

\section{ABSTRACT}

Hypothesis: Senior hospital clinicians are poorly engaged with clinical coding and hospital episode statistics (HES).

Aims:

- To understand the current level of clinical engagement with collection of national data and clinical coding.

- To gain the views of frontline staff on proposed improvements to hospital statistics.

- To gain an indication of likely clinical engagement in change.

- To understand the clinical priority for improvement.

Design: Internet e-survey accessible from Academy of Royal Medical College Website.

Setting: National Health Service (NHS) Trusts.

Participants: 1081 NHS hospital consultants and two general practitioners who volunteered to take part.

Results: $3.4 \%$ of the sample regularly access HES data; $21 \%$ are regularly involved in clinical coding and $6.2 \%$ meet coding staff at least monthly. $95 \%$ would like to access HES data and there was a strong support for using this data for appraisal, revalidation and improving the quality of patient care. In terms of improvements, $91.9 \%$ would be prepared to code diagnosis in outpatients given the right tools. The highest priority for improvement is clinical validation of diagnostic data.

Conclusions: Clinical engagement with coding and access to HES data is poor. However, there is professional support for improvement. Clinical requirements should be considered in all future developments of national data collection to provide the quality and scope of data that is required to deliver the information revolution.

\section{INTRODUCTION}

The appetite for high-quality clinical information in the National Health Service (NHS) has never been higher. There is a requirement to measure the quality of care and provide patients with a clear view of how

\section{ARTICLE SUMMARY}

Article focus

- A professional response to a series of proposed changes to national data collection is reported.

Key messages

- There is a serious lack of clinical engagement with clinical coding and hospital episode statistics.

- There is a widespread support for the proposed enhancement to the hospital episode statistics dataset (which would make the data more clinically relevant and accessible).

- A strong appetite for using the national data for revalidation and quality improvement is demonstrated.

Strengths and limitations of this study

- A large number of respondents across all specialities in England were obtained.

- The survey was conducted following a widespread consultation through the Academy of Medical Royal Colleges and Medical Directors.

- Only $2.8 \%$ of the target workforce responded, so the results may not be fully representative.

services compare. The current set of reforms is entirely predicated on the availability of good quality, timely information to manage and commission effectively. ${ }^{1}$ Unexplained variability in service quality and outcomes has been identified as a significant issue. ${ }^{2}$ The recent white paper has called for a greater transparency including the provision of access by patients to their electronic records. ${ }^{3}$ NHS Choices is publishing metrics and quality indicators based largely upon hospital episode statistics (HES). ${ }^{4}$ The same data is used though linkage to Office of National Statistics to monitor hospital mortality by the calculation of the Hospital Standardised Mortality Ratio, ${ }^{5}$ augmented by the Standardised Hospital Mortality Index. ${ }^{6}$ The success of the outcomes framework ${ }^{1}$ requires good-quality data. 
Therefore, it is a matter of some considerable concern that clinical engagement with the collection of national data for secondary use is generally believed to be poor. ${ }^{78}$ The current data-collection system was set up following the Korner report 'Data for Management' in $1982 .{ }^{9}$ Douglas Black, the then president of the Royal College of Physicians (RCP), in a leading article pointed out the benefits of clinical coding for medical practice. ${ }^{9}$ For many years the data was collected from in-patients by the completion of the Korner forms which were often used as a poor, sometimes illegible, discharge summary for the general practitioner. Highly skilled clinical coders are required to convert clinical diagnostic terms gleaned from the notes or Korner returns into International Classification of Diseases V.10 (ICD-10) and interventions into Office of Population Censuses and Surveys Classification of Surgical Operations and Procedures V.4.5 (OPCS-4.5) for entry through the Trusts Patient Administration Systems into a British Telecom database called Secondary User Services (SUS). Since the introduction of Payment by Results (PbR) the terms have also been put through a grouper to create the necessary Health Resource Groups for the purposes of reimbursement. Extracts of SUS data are anonymised and cleaned and made available by the NHS Information Centre (NHS-IC) for secondary use as HES data. Successive audit reports have indicated considerable problems with data completeness, accuracy of clinical coding and engagement of clinicians ${ }^{78}$ even following the introduction of PbR. ${ }^{10}$ Generally speaking, clinical coders are well trained and very accurate in converting clinical terms into codes, ${ }^{11}$ the problem is that it is difficult for them to extract the correct information from unstructured clinical notes. To this end the Health Informatics Unit of the RCP has published standards for structured medical records ${ }^{12}{ }^{13}$ which have been published by the Academy of Medical Royal Colleges (AOMRC).

All these problems and more have been described in detail in a discussion paper which has been endorsed by the AOMRC. ${ }^{14}$ This discussion paper suggests a number of areas for improvement that have been deemed necessary to improve clinical engagement (box 1). Since the inception of HES, the health service has changed considerably, but very little has been done to make HES fit for modern clinical requirements. As purely 'data for management' and as a means to provide the World Health Organisation (WHO), the owners of ICD10, with a crude overview of disease prevalence in the UK compared with the rest of the world, it has been highly successful. Requirements have changed, and now that monitoring quality of service and outcomes is a high priority for the NHS, there is a need to have a national data collection to support this. Furthermore, the spectre of revalidation has left Trusts and Colleges looking for independent data that could be used to support this process. There are alternative data sources such as national audits, disease registers, specialty datasets and national specialist systems, all of which have been developed to provide high-quality
Box 1: In the survey clinicians were asked to respond to the above improvements which had been recommended in a discussion paper published online by the AOMRC. ${ }^{14}$

- Providing clinicians with an access to their raw data for the purposes of review and validation.

- Recording of clinical terms (SNOMED) in addition to ICD10 and OPCS for detailed audit, analysis and validation of codes used.

- Capture of diagnostic and procedure information in outpatients.

- Capture clinicians including non-consultant career-grade doctors, undertaking medical or surgical activities in addition to the consultant in-charge so as to represent the current way in which senior clinicians work in teams.

- A diagnosis present on admission flag to differentiate between events such as a broken leg, a pressure sore and acquisition of MRSA occurring prior to or during a hospital stay.

- Easier and more cost-effective linkage of other databases to HES.

- Linking primary and secondary care records.

ICD, International Classification of Diseases; HES, hospital episode statistics; SNOMED, systematized nomenclature of medicine; MRSA, methicillin resistant staphylococcus aureus; OPCS, Office of Population Censuses and Surveys.

clinical data to improve quality of care. In contrast to HES these systems normally attract a high level of clinical engagement and some of them have benefited from linkage to HES. ${ }^{15}$ However, these data are not comprehensive, leading to a situation where some practitioners have excellent information about their service including the quality of patient care and others have none. The benefit of high-quality clinical data has been demonstrated by the year-on-year improvements in outcome following a cardiac surgery. ${ }^{16} 17$

In this context and following the publication of 'Improving the quality and value of HES-a discussion document ${ }^{14}$ a national survey was undertaken jointly by the AOMRC and The Information Centre for Health and Social Care (NHS-IC) with the following main aims:

1. To understand the current level of clinical engagement with collection of national data and clinical coding.

2. To gain the views of frontline staff on proposed improvements to hospital statistics.

3. To understand the clinical priority for improvement.

4. To gain an indication of likely clinical engagement in change.

\section{METHODS}

A survey was developed to address the above issues using Survey Monkey. The survey consisted of 15 closed questions about attitudes to HES and clinical coding and five questions about the respondents' professional activities. Throughout the survey there was plenty of space allocated for free text comments. Through NHS, London, 
the survey was piloted and 16 clinicians completed the survey. There was an additional question in the pilot survey about the value of the survey and any problems or ambiguities experienced in completing the questions. The response to the pilot was favourable and a few minor modifications were made based on the comments received. The survey was cleared and a link was created from the AOMRC website. In addition, there was also a link from the text of the discussion document. The survey was promoted through regional medical directors who were all asked to request that Trust medical directors recommend the survey to all their consultant medical staff. Also the Royal Colleges were approached about promoting the survey to their members through newsletters, websites, email and any other means at their disposal. The British Medical Association (BMA) agreed to support the survey and it was included in a BMA newsletter and in one edition of the BMA News Review. The survey was active from 12 April 2011 to 28 October 2011 and reminders were sent out part way through the survey.

In analysing the results, responses from partially completed questionnaires where questions had been skipped were included. For each question the number of respondents is recorded, the percentages relate to the proportion selecting an option out of those who answered the question. The specialty of the respondent was requested from the list of NHS, Main Speciality Codes. ${ }^{18}$ For the purposes of analysis and presentation these were collated into broad groupings. In a question where respondents were asked to rank a maximum of five developments out of a list of 17 suggestions, the rankings were converted to a score of five for the highest rank, four for the next and so on down to one for the lowest. No score was allocated for the rest of the 12 suggestions not ranked. The scores for each development were summated to provide a single numerical value for each (figure 1 ).

\section{Ethics}

The survey was an anonymous voluntary survey of NHS senior staff and therefore neither an ethical approval nor a patient consent was required.

\section{RESULTS}

In total, 1083 out of approximately 39088 consultants in England ${ }^{19}$ responded to the survey $(2.8 \%)$. Not every participant answered every question, the response rate for individual questions ranged between $99.6 \%$ and $77.8 \%$ excluding one question which only a proportion of the cohort were eligible to reply based on the answer to a previous question. The professional status of those providing the information is shown in table 1 . The survey questions and responses are shown in tables 2 and 3. In total, 191 (17.7\%) of participants who read the AOMRC discussion document thoroughly, another $750(69.5 \%)$ read the executive summary. Of the 747 respondents expressing a view, $99.9 \%$ agreed that key issues in box 1 required a

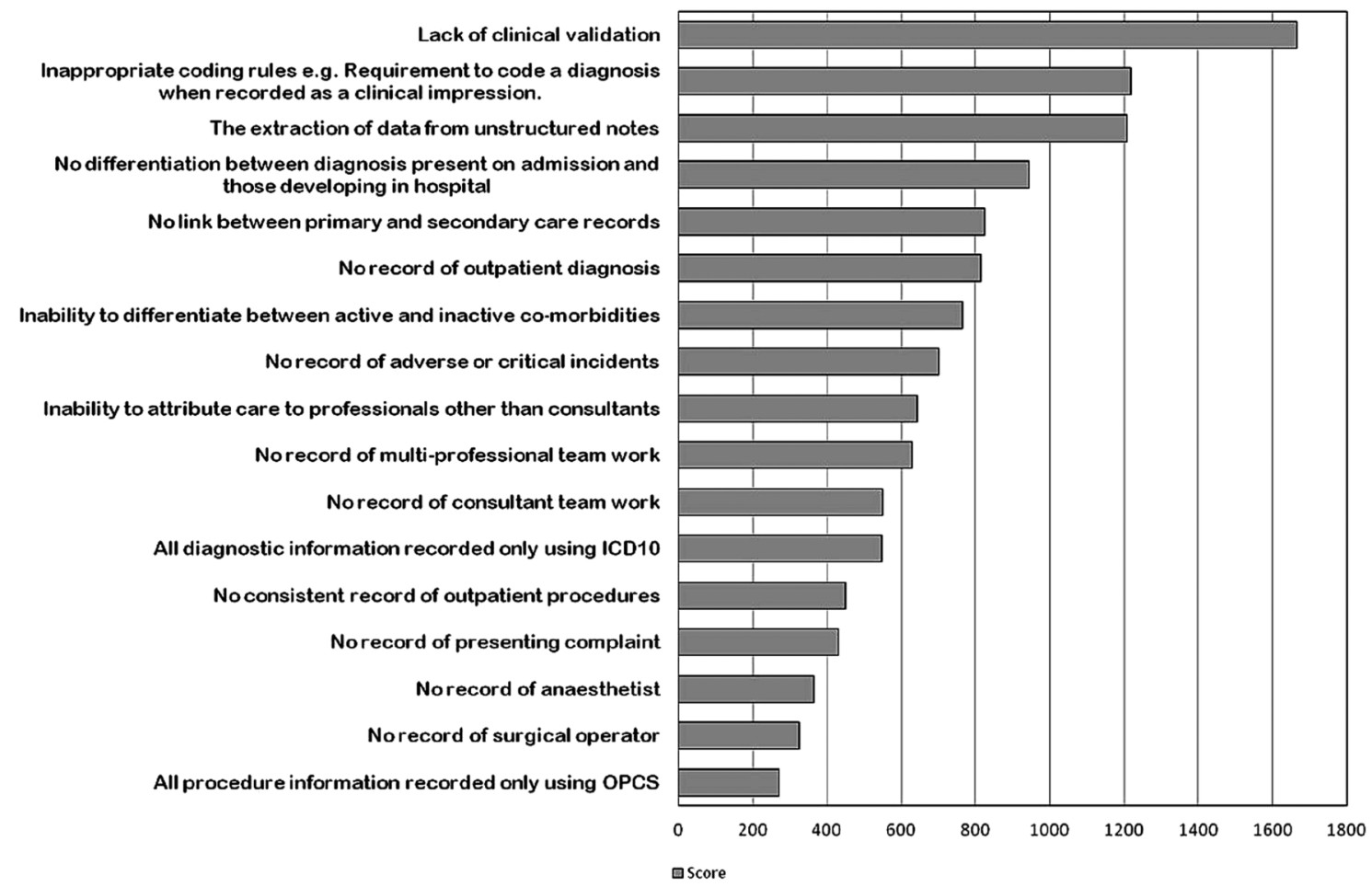

Figure 1 Priorities for hospital episode statistics development. Respondents were asked to rank a maximum of 5 developments out of the 17 shown. The rankings were converted to a score of five for the highest rank, four for the next and so on down to one for the lowest. No score was allocated for the 12 suggestions not ranked. The scores for each development were summated to provide a single numerical value. 
Table 1 Professional information about respondents

\begin{tabular}{llrc}
\hline Respondants & Responses & No & Per cent \\
\hline Consultant & 873 & 819 & 93.8 \\
Associate specialist & 873 & 20 & 2.3 \\
Medical director & 871 & 38 & 4.4 \\
Clinical director & 871 & 175 & 20.1 \\
Clinical lead & 871 & 323 & 37.1 \\
Academic position & 849 & 281 & 33.1 \\
In-patient practice & 869 & 694 & 79.9 \\
Medical specialty & 864 & 251 & 29.1 \\
Surgical specialty & 864 & 204 & 23.6 \\
Paediatircs & 864 & 133 & 15.4 \\
Anaesthetics & 864 & 119 & 13.8 \\
Obs \& gynae & 864 & 41 & 4.7 \\
Mental health & 864 & 44 & 5.1 \\
Emergency medicine & 864 & 28 & 3.2 \\
Other speciality & 864 & 10 & 1.2 \\
\hline
\end{tabular}

solution; 140 (16.6\%), $383(45.4 \%)$ and 319 (37.8\%) thought that this applied to some, most or all, respectively. It is clear that only about $20 \%$ of doctors have found HES useful and about $75 \%$ have never attempted to access their HES data or have tried unsuccessfully. In the small number where HES data has been accessed, it is mainly Trusts that have provided the presubmission data, although external providers have played a significant role. On the other hand, $85 \%$ would like to be able to access data on their patients; the reasons given included monitoring quality of care, monitoring patient outcomes, annual appraisal and revalidation in over $80 \%$ of respondents. The question did contain a caveat about HES being of sufficient quality to support these uses. Twenty-two per cent are involved in clinical coding regularly but another $39 \%$ have been involved occasionally (table 3). A subanalysis demonstrated that it is small numbers from a wide range of specialties that are involved in regular clinical coding rather than a particular specialty or group of specialties that are engaged in this activity. Regular engagement with clinical coding staff is extremely rare, but $92 \%$ of the respondents were positive about undertaking outpatient coding with the appropriate tools. Clinicians involved in management were more likely to respond 'certainly yes' to this question, the percentages were $76 \%$ for medical directors, $59 \%$ for

Table 2

\begin{tabular}{|c|c|c|}
\hline Survey questions about HES & No & Per cent \\
\hline What did you think of HES before reading the paper? & 948 & \\
\hline I had never heard of it & 162 & 17.1 \\
\hline I thought it of no relevance to me & 106 & 11.2 \\
\hline Might be useful & 476 & 50.2 \\
\hline I found it useful in my work & 145 & 15.3 \\
\hline It was of the utmost importance to me & 59 & 6.2 \\
\hline Have you ever attempted to review HES data attributed to your care of patients? & 952 & \\
\hline No & 531 & 55.8 \\
\hline Yes, but unsuccessfully & 179 & 18.8 \\
\hline Yes, succesfully as a one off & 57 & 6.0 \\
\hline Yes, successfully on an occasional basis & 153 & 16.1 \\
\hline Yes, succesfully on a regular basis & 32 & 3.4 \\
\hline *If you were able to access the data, who provided it? & 249 & \\
\hline Your Trust Information Service & 195 & 78.3 \\
\hline Regional, eg, Quality observatories & 27 & 10.8 \\
\hline Royal College of Physicians & 3 & 1.2 \\
\hline NHS-IC HES team or Extraction Services (Northgate) & 9 & 3.6 \\
\hline External provider, eg, Dr Foster/CHKS & 107 & 43.0 \\
\hline Other & 30 & 12.0 \\
\hline Would you like to be able to view the HES data attributed to your care of patients? & 942 & \\
\hline No & 50 & 5.3 \\
\hline Maybe, Yes & 340 & 36.1 \\
\hline Certainly Yes & 552 & 58.6 \\
\hline Which of the following would you like to use HES data to support?* & 939 & \\
\hline Evidence for annual appraisal & 803 & 85.5 \\
\hline Evidence for revalidation & 760 & 80.9 \\
\hline Application for Clinical Excellence Awards & 509 & 54.2 \\
\hline To monitor quality of patient care & 819 & 87.2 \\
\hline To monitor patient outcomes & 811 & 86.4 \\
\hline To benchmark local services with others & 727 & 77.4 \\
\hline To select patient for research studies & 237 & 25.2 \\
\hline
\end{tabular}

*More than once answer may be selected by participants.

HES, hospital episode statistics. 


\section{Table 3}

\begin{tabular}{|c|c|c|c|}
\hline Survey questions about clinical coding & Responses & No & Per cent \\
\hline What is your involvement in clinical coding? & 888 & & \\
\hline I had never heard of it & & 5 & 0.6 \\
\hline I thought it of no direct relevance to me & & 29 & 3.3 \\
\hline I think it is important but it doesn't involve me & & 316 & 35.6 \\
\hline I am occasionally involved & & 344 & 38.7 \\
\hline I am regularly involved & & 194 & 21.8 \\
\hline Do you have any involvement with clinical coding staff in your Trust? & 890 & & \\
\hline None & & 399 & 44.8 \\
\hline 1 or 2 meetings in total & & 178 & 20.0 \\
\hline Occasional meetings & & 258 & 29.0 \\
\hline Monthly meetings & & 30 & 3.4 \\
\hline Weekly meetings (eg, regular ward rounds) & & 25 & 2.8 \\
\hline Would you be prepared to code top 50 diagnoses in outpatients? & 880 & & \\
\hline No & & 72 & 8.2 \\
\hline Maybe, Yes & & 327 & 37.2 \\
\hline Certainly Yes & & 481 & 54.7 \\
\hline Do you use structured records? & 878 & & \\
\hline No & & 509 & 58.0 \\
\hline Yes & & 343 & 39.1 \\
\hline Yes-Conforms to AOMRC standards & & 26 & 3.0 \\
\hline
\end{tabular}

clinical directors, $56 \%$ for clinical leads and $49 \%$ for those who have had no management responsibility. Although the use of structured records, which can assist clinical coders, is quite common very few adhere to the standards published by the AOMRC (table 3).

In response to a question about future changes to HES a wide range of developments were prioritised (figure 1). This is partly indicative of the wide range of specialties involved in completing the survey. For example, of the 40 respondents who ranked 'no record of anaesthetist' as their number one priority 39 were anaesthetists. Overall lack of clinical validation of coding was the highest priority for resolution with many other technical problems with coding scoring most highly.

On the question of personal involvement with validation of notes, $52 \%$ and $45.7 \%$ always or regularly validated the diagnosis and procedure, respectively; $9 \%$ and $7.2 \%$ claimed this level of validation for ICD10 and OPCS codes. On the subject of instructing juniors on the importance of accurate record keeping, $84 \%$ did this regularly for clinical notes compared with $23.7 \%$ for clinical coding and $6.6 \%$ for HES.

There were 171 comments in relation to the AOMRC paper and the key issues. The comments were extremely wide-ranging and difficult to summarise in detail. 64 comments related to which of the seven issues were agreed or not agreed by the respondent and prioritisation from their own professional perspective. Fourteen respondents relayed their own personal experiences of using data. In terms of broad themes there was much discussion about the role of the consultant in ensuring the accuracy of data collection in their patients with at least eight feeling this was unfair to the point of expressing anger/irony in some cases:

I dislike the tone of the paper. To say that this issue is the 'responsibility' of clinicians (which we have by implication-abrogated) is insulting.

I'm delighted that something else is now 'my responsibility', how foolish of me to think that actually seeing and treating patients was the job of a Dr rather than sitting coding.

Another 21 respondents raised the problem of shortage of consultant time in the job plan for these activities or lack of prioritisation in the Trusts:

It is true that clinicians need to take responsibility for the accuracy of coding BUT Trusts (in my opinion) see this a low priority on clinician time (ie reflected in their actual job plans).

Seven thought clinicians were only disengaged because of Trust processes:

However most of us work hard within the NHS and if we are disinterested in data it is because we are excluded from the process ("it is too expensive to pay consultants to spend time on ensuring data accuracy'), or that we all realise that NHS IT is utterly useless and no-one ever seems to be able to put it right (despite the fact that there are simple solutions).

A further 18 pointed out the inadequacy of current Electronic Patient Record (EPR) systems and the belief 
that data could not be improved until this problem had been solved.

Small number of comments related to specialtyspecific data collection, either its value of lack of availability and lack of data and hence clinical engagement was identified as a problem for anaesthetics, interventional radiology, community paediatrics and sexual health.

On the question of previous views of HES data there were 279 comments, of which 107 relayed experience or perception of inaccurate data. This was often expressed in terms of the data being rendered useless for any local clinical application:

HES data are so frequently wrong when we review them that we despair of their use for anything.

Despite the perception of inaccuracy, those specialties without HES data felt aggrieved that this was responsible for devaluation of their service:

\begin{abstract}
Because our specialty-community paediatrics—did not appear in it even when the HES outpatient ran in 2006. This trivialises outpatient work and provides no incentive not to admit patients or for juniors, to work in a specialty which tries to keep patients out of hospital beds. Therefore there was an assumption that community paediatrics was like hospital based paediatrics, and the only HES data available was used by external reviewers like MacKinsey to criticise our service; based on those numbers they suggested doctors should be replaced by therapists.
\end{abstract}

At the end of the survey there were 168 further comments again wide-ranging and diverse. The main themes included the need for simple data collection systems and structured records (22), clarification of previous answers (20), consultant time/workload, funding, resource issues (17), codes, clinical coders and clinicians and coding rules (16), sceptical about change (14) and information about local systems/implementation problems (10).

Many of the issues expressed are brought out in the quote below:

That outpatient data is not collected in any form is madness! For coding, the key interaction is between clinician and coder, and the two rarely (if ever) meet. To improve the situation, the Trusts have to see data collection as central and worth investing in, which in turn has implications for the job planning of clinicians.

\section{DISCUSSION}

The results of this survey support previous publications $781^{10} \quad 20-22$ demonstrating the stark reality that clinicians are significantly divorced from their data in respect of poor access to HES and a lack of involvement in clinical coding. A recent letter to the British Medical Journal not only emphasised this point, but was also taken up by the national press. ${ }^{23}$ Surveys do have limitations however, and this study is open to criticism on the basis of the sample size which represents only about $2.8 \%$ of consultants and may not be representative of the average consultant. Although it is not possible to speculate on the views of those who did complete the questionnaire, the comments suggest that many of the respondents had a particular interest in data, at least in their specialty. Despite limitations the study does represent the timeliest and most complete picture of clinician involvement in national data collection and the vast number of comments offers a unique insight into consultant attitudes and aspirations for a better future. Attainment of over 1000 responses represents a major achievement in an area where disinterest and lack of engagement from consultants is common. To obtain this level of response required leverage through Medical Directors, encouragement from the Royal Medical Colleges and support from the BMA. It is difficult to imagine what else could be done to increase the response rate. The validity of the results are strongly supported by previous studies 78 and the fact that the quality of clinical data in HES remains an on-going concern. ${ }^{10}$

In the NHS some unhelpful artificial distinctions in the types of information collected have been created. Management information is largely used for performance and financial purposes, clinical information is supported by registries and clinical audit and organisational information describes the institution that delivers care. Patient information describes those receiving that care. Unfortunately, it has proven very difficult to bring these together.

The aspirations of the National Programme for IT were to establish electronic health records in every care setting. This would have allowed information to flow automatically to support a secondary use as a by-product of care. The clinical process assures the quality of the information collected in this scenario. While this is a goal to work towards and is achievable as demonstrated by some trusts, it will take time to establish universal comprehensive electronic patient records (EPRs) in all Trusts.

In the intervening period, data collections such as HES will continue to be used to run the NHS. To make 'quality the operating principle of the NHS' as described by David Nicholson, Chief Executive of the NHS in $2009,{ }^{24}$ the data on which financial flows are based must be assured by clinical teams. It is with that in mind that this survey was carried out to establish the relationship between secondary care clinicians and the data that purports to describe the activity for which they are responsible. There is a strong view that if HES data were owned, valued, used and assured by clinicians then the data quality would improve and could be used for various purposes including quality assurance, patient safety, revalidation and appraisal. As one medical director puts it this way;

As Medical Director I believe good quality HES is essential for purposes of Revalidation and Appraisal, but especially with regards monitoring clinical outcomes and patient safety. 
Unfortunately, lack of clinical validation remains a problem for HES as shown by its selection as the top problem with HES. In this survey, almost half of the consultants had never had any contact with their coders. There exists a cultural, professional and often a geographic gap between consultants and those coding the clinical records.

Urgent work is needed to connect secondary clinicians with their data. Making changes to HES to make it more accessible, relevant and useful to clinicians is an important first step. The survey demonstrates support for clinician-led outpatient coding provided that appropriate easy-to-use tools are provided. There is also support for attributing named clinicians to each surgical and anaesthetic procedure.

Although HES can never fully satisfy the need for clinical databases, as long as HES is used to manage the financial flows, we must work to align more closely the two parallel worlds of finance and clinical activity.

It is essential that this survey is not just another description of systemic data problems in the NHS; the purpose of the survey was to provide essential timely data to support major changes to data collection. Unfortunately, making changes to the national clinical dataset is difficult and expensive, not only are changes required to SUS to make the data flow, but also disparate Trust systems have to be modified in order for the new data to be collected locally and exported into SUS. Perhaps the most difficult of all is the cultural change that is required to enable accurate data to flow from the doctor-patient interface.

Despite these problems, it is now widely acknowledged within the NHS-IC and the Department of Health Informatics Directorate that change is needed if the prize of clinical engagement is to be achieved. Such change will require a substantial programme of work and substantial resources. Clinician recording of diagnosis and presenting complaint in outpatients will require the development of systematized nomenclature of medicine - clinical terms (SNOMED-CT) specialty subsets for the common conditions with agreed definitions. Initially, the data can flow using local mapping to ICD10, but in time the aspiration is to flow the data nationally in SNOMED and to ensure that this is aligned with the diagnostic data populating the clinic letter. Recording of an anaesthetist and surgeon involved in each procedure is theoretically quite simple, but it will require the development of additional fields in SUS plus local work in every Trust to export this information from theatre systems or paper records. Although there are no guarantees, there are signs that change is on the horizon. It is our hope that high-level clinical engagement combined with change to the national data collection will achieve a major improvement in data quality that will support continuous improvement in patient care and subsequent outcomes. In the future, it is imperative that changes and developments to all future releases of national collection systems such as SUS include clinical requirements so that a cycle of continuous improvement in data quality and clinical relevance develops and is maintained.
In conclusion, the survey demonstrated a low level of engagement by respondents with clinical coding and HES. Virtually all respondents agreed with all or some of the proposed improvements to HES. A high level of clinical support for change was indicated by willingness to code in outpatients and interest in viewing and using HES data. The highest clinical priorities around improvement related to perceived problems with clinical coding.

Protocol The survey questions are available on request from the corresponding author andy.spencer@doctors.net.uk

Contributors SAS as the lead author was responsible for the design and conduct of the survey and analysis of the results with a regular support and advice from MPD. The paper was written jointly by SAS and MPD and both approved the final manuscript.

Funding This research received no specific grant from any funding agency in the public, commercial or not-for-profit sectors.

\section{Competing interests None.}

Ethics approval This is a voluntary anonymous e-survey of consultants views and as such ethical permission was not required.

Provenance and peer review Not commissioned; externally peer reviewed

Data sharing statement Responses to all questions and all free text comments available from the corresponding author at andy.spencer@doctors. net.uk Consent was not obtained for data sharing but the presented data was submitted anonymously so that the contributors cannot be identified.

\section{REFERENCES}

1. Department of Health. Liberating the NHS: Transparency in outcomes - a framework for the NHS. 2010. http://www.dh.gov.uk/ prod_consum_dh/groups/dh_digitalassets/@dh/@en/documents/ digitalasset/dh_117591.pdf

2. Mays N. Reducing unwarranted variations in healthcare in the English NHS. BMJ 2011;342:665.

3. Department of Health. Equity and excellence: Liberating the NHS, 2010. http://www.dh.gov.uk/prod_consum_dh/groups/dh_ digitalassets/@dh/@en/@ps/documents/digitalasset/dh_117794.pdf (accessed 6 Nov 2012)

4. NHS Choices, Your health, your choices. http://www.nhs.uk/Pages/ HomePage.aspx (accessed 6 Nov 2012)

5. Jarman B, Gault S, Alves B, et al. Explaining differences in English hospital death rates using routinely collected data. BMJ 1999;318:1515-20.

6. Keogh B, Dalton I. National Review of Hospital Standardised Mortality Ratios (HSMR), 2010 (cited 2011 Aug. 11). http://www.dh. gov.uk/prod_consum_dh/groups/dh_digitalassets/documents/ digitalasset/dh_121353.pdf (accessed 6 Nov 2012)

7. Audit Commission. Data remember improving the quality of patient-based information in the NHS. Audit Commission Publications, 2002. http://www.audit-commission.gov.uk/ nationalstudies/health/other/Pages/dataremember.aspx (accessed 6 Nov 2012)

8. Audit Commission. Information and data quality in the NHS, 2004 http://www.audit-commission.gov.uk/nationalstudies/health/other/ Pages/informationanddataqualityinthenhs.aspx (accessed 6 Nov 2012)

9. Black D. Data for management: the Korner Report. BMJ 1982;285:1227-8.

10. Audit Commission. PbR data assurance framework 2008/09, 2009 http://www.audit-commission.gov.uk/nationalstudies/health/pbr/ pbrdataassuranceframework200809/Pages/default.aspx (accessed 6 Nov 2012)

11. Burns EM, Rigby E, Mamidanna R, et al. Systematic review of discharge coding accuracy. J Public Health (Oxf) 2011;34:138-48.

12. Health Informatics Unit RCP. A Clinician's Guide to Record Standards-Part 1: Why standardise the structure and content of medical records? Digital and Health Information Policy Directorate, 2008. http://www.rcplondon.ac.uk/sites/default/files/clinicians-guidepart-1.pdf (accessed 6 Nov 2012)

13. Health Informatics Unit RCP. A Clinician's Guide to Record Standards-Part 2: Standards for the structure and content of 
medical records and communications when patients are admitted to hospital. Digital and Health Information Policy Directorate, 2008. http://www.rcplondon.ac.uk/sites/default/files/documents/cliniciansguide-part-2-standards.pdf (accessed 6 Nov 2012)

14. Spencer SA. Hospital Episode Statisitics (HES): Improving the quality and value of hospital data: A discussion document, 2011. http://aomrc.org.uk/publications/reports-a-guidance/doc_download/ 9379-hospital-episode-statistics-improving-the-quality-and-value-ofhospital-data-discussion-document.html (accessed 6 Nov 2012)

15. Sibanda N, Copley LP, Lewsey JD, et al. Revision rates after primary hip and knee replacement in England between 2003 and 2006. PLoS Med 2008;5:e179.

16. Bridgewater B, Grant S, Hickey G, et al. NICOR: National Institute for Cardiovascular Research; National Adult Cardiac Surgery Audit Annual Report 2010-2011. http://www.hqip.org.uk/Bridgewaassets/ NCAPOP-Library/NCAPOP-2012-13/Adult-Cardiac-Surgery-Report2010-11-published-2012.pdf (accessed 7 Nov 2012).

17. Bridgewater B, Cooper G, Livesey S, et al. Maintaining Patients' Trust: Modern Medical Professionalism, 2011. http://www.scts.org/ userfiles/resources/634420268996790965 SCTS

Professionalism_FINAL.pdf (accessed 7 Nov 2012)

18. Main Speciality Code. http://www.datadictionary.nhs.uk/data dictionary/attributes $/ \mathrm{m} / \mathrm{main} \_s p e c i a l t y \_c o d e \_d e . a s p ? q u e r y=$ main $\%$ 20 specialty\%20codes\&rank=1\&shownav $=1$ (accessed 6 Nov 2012)
19. Health and Social Care Information Centre, Workforce and Facilities Team. NHS Workforce:Summary of Staff in the NHS: Results from September 2011 Census, 2012. http://www.ic.nhs.uk/webfiles/ publications/010 Workforce/NHS\%20STAFF\%20ANNUAL\%20200111/NHS_Workforce_Census_Bulletin_2001_2011.pdf (accessed 7 Nov 2012)

20. Croft GP, Williams JG. The RCP Information Laboratory (iLab): breaking the cycle of poor data quality. Clin Med 2005;5:47-9.

21. Croft GP. The iLab project evaluation report. 2006. http://www. rcplondon.ac.uk/sites/default/files/ilab-full-report_2.pdf (accessed 7 Nov 2012)

22. Croft GP. Engaging clinicians in improving data quality in the NHS 2006 (cited 2010 June 4). URL:http://www.wales.nhs.uk/sites3/ Documents/920/Engaging\%20clinicians\%20in\%20improving\% 20data\%20quality\%20in\%20the\%20NHS.pdf (accessed 7 Nov 2012)

23. Brennan L, Watson M, Klaber R, et al. The importance of knowing context of hospital episode statistics when reconfiguring the NHS. BMJ 2012;344:e2432-3.

24. Department of Health. The NHS in England: the operating framework for 2008/9. 2010 (cited 2010 May 6).http://www.dh.gov. uk/prod_consum_dh/groups/dh_digitalassets/@dh/@en/documents/ digitalasset/dh_081271.pdf (accessed 6 Nov 2012). 